\title{
A comprehensive workflow for real time injection-production optimization based on equilibrium displacement
}

\author{
Huijiang Chang ${ }^{1 \oplus *}$, Yingxian Liu ${ }^{1}$, Yuan Lei $^{1}$, Qi Zhang ${ }^{2}$ \\ ${ }^{1}$ Bohai Oilfield Research Institute, Tianjin of CNOOC Ltd., Tianjin 300459, P. R. China \\ ${ }^{2}$ Faculty of Earth Resources, China University of Geosciences, Wuhan 430074, P. R. China
}

Keywords:

Equilibrium displacement

plane injection and production adjustment

eurytopic water drive curve

real-time optimization

Bohai BZ oilfield

Cited as:

Chang, H., Liu, Y., Lei, Y., Zhang, Q. A comprehensive workflow for real time injection-production optimization based on equilibrium displacement. Advances in Geo-Energy Research, 2020, 4(3):

260-270, doi: 10.46690/ager.2020.03.04.

\begin{abstract}
:
Irregular well network with high oil recovery rate is used in the development of offshore oilfield, which usually leads to imbalanced waterflooding and poor development performance. In this paper, according to the Buckley-Leverett Equation and general waterflooding theory, a quantitative relationship between water-cut, liquid production and water injection rate is gained to improve the unbalanced lateral waterflooding of the present well network. All the single-well water-cuts are considered to obtain balanced waterflooding of present well network through liquid production and water injection rate adjustments. A new injection-production adjustment method is proposed, with the corresponding calculation program being compiled to realize real-time optimization and adjustment. This method is applied to the 1-1195-1 sand body of Bohai BZ Oilfield. The daily oil increment is 80 $\mathrm{m}^{3} / \mathrm{d}$ and the cumulative annual oil increment is $2.6 \times 10^{4} \mathrm{~m}^{3}$, which is consistent with the expected program. It can therefore contribute to engineers' optimizing the injectionproduction strategy of reservoirs, as well as facilitating revitalizing mature water foods and, more importantly, facilitating the design and implementation of an appropriate Improved Oil Recovery pilots. The presented reliable method could provide certain significance for the efficient development of offshore oilfields.
\end{abstract}

\section{Introduction}

Because of the characteristics of progressive development in offshore oil fields, high speed development of irregular well pattern in offshore oil fields often causes unbalanced displacement, and even inefficient circulation of injected water along the high-permeability direction, which affects the overall development effect of the oilfield. The degree of equilibrium displacement is closely related to the effect of oilfield development (Alhuthali et al., 2007; Liu et al., 2014; Omara et al., 2014; Tailai et al., 2014). Therefore, increasing attention has been paid to reducing the influence of high production rate on water-drive, adjusting and rebuilding injection-production system of water-drive, improving water-drive effect and realizing equilibrium displacement. Under the condition of existing well pattern, scholars have carried out a lot of research on the equilibrium adjustment method for injection and production of oil and water wells, with series of adjustment methods of liquid production and water injection rate being proposed.
Numerical reservoir simulation is a valuable but a computationally expensive tool for the design, evaluation and operation of hydrocarbon fields. Such reservoir models are complex, time consuming, uncertain, and based on limited information. By using the geological model, the predecessor matched the production data through streamline simulation (Thiele et al., 1996; Batycky et al., 1997; Denney, 2001; Baker et al., 2002; Park and Datta-Gupta, 2013) and analyzed the fluid movement law and flow trajectory. Compared with the conventional method of determining the strength of the flow field based on the pore saturation distribution, streamline simulation can more accurately and intuitively display the main flow area of the fluid. In addition, water flooding reservoirs can be optimized for water flooding, water flooding control, and well pattern optimization considering the injector allocation factor (Bostan et al., 2013; Wen et al., 2014; Sajjadi et al., 2017; Hu and $\mathrm{Li}, 2018$ ).

Quick evaluation of reservoir performance is one of

\section{Yandy
Scientific}

Press
* Corresponding author.

E-mail address: changhj2@cnooc.com.cn (H. Chang); liuyx3@cnooc.com.cn (Y. Liu); leiyuan@cnooc.com.cn (Y. Lei);

zhangqi6242006@163.com (Q. Zhang).

2207-9963 (c) The Author(s) 2020.

Received May 19, 2020; revised June 12, 2020; accepted June 13, 2020; available online June 17, 2020. 
the main concern in decision-making. Time-consuming data preparation and processing, and data uncertainty (geological, petrophysical and reservoir engineering) limit the application of numerical simulators in addition to long-term response to reservoir management. Effective reservoir management needs quick action on the distribution of injected fluid to improve the areal and vertical sweep efficiency in the process of secondary and tertiary oil recovery. Therefore, it is of great significance for reservoir monitoring and management to use simple and rapid methods to supplement or replace reservoir simulation. Researchers have used reduced-physics and data-driven technologies to quickly build and match a reservoir model that can be used to optimize waterfloods (Brouwer and Jansen, 2004; Jansen et al., 2005; Chen et al., 2009; Van Essen, et al., 2009; Cardoso and Durlofsky, 2010; Hu, 2013; Lerlertpakdee et al., 2014; Artun, 2017). Capacitance Resistance Model (CRM) (Yousef et al., 2006; Sayarpour et al., 2009; Chen et al., 2010) is one proven method to address the above challenges. The CRM model is based on hypothesis that reservoir performance can be inferred from analyzing production and injection data and a simplified analytic model structure. Strategies derived from CRM model the increased production with associated water cut reduction just by reallocating injection rates (Nguyen et al., 2011; Mamghaderi et al., 2013; Cao et al., 2015; Hong et al., 2017). The interwell numerical simulation model (INSIM) (Guo et al., 2018a; Guo and Reynolds, 2019) is one a calculation tool to approximate the performance of a reservoir under waterflooding. In INSIM, the reservoir is characterized as a coarse model consisting of a number of interwell control units, each of which has two specific parameters, transmissibility and control pore volume. By solving the mass material balance and front tracking equations for the control units, the interwell fluid rates and saturations are obtained so that phase producing rates can be predicted. Historical matching and parameter estimation are carried out by adopting INSIM to infer the interwell connectivity and geological characteristics (Guo et al., 2018b; Guo and Reynolds, 2019; Zhao et al., 2019, 2020).

It is difficult for most of these methods to achieve quantitative calculation. With some quantitative calculation methods being put forward, the effect of injection-production adjustment for simplification of actual oil deposit and production process still needs improvement. Therefore, based on the equation of Buckley-Leverett, combined with the theory of an eurytopic water-drive, and considering factors of the real situation of the reservoir, the actual production process and irregular well pattern, aiming at same water cut of all single wells, a new method of quantitative injection-production adjustment in the plane is put forward, being suitable for various well patterns and exerting a great guiding influence on the adjustment of injection-production structure in oil fields.

\section{Injection-production optimization workflow}

With proposed workflow having been designed to provide quick optimization of water flooded reservoirs, optimization results can be obtained with minutes to hours depending on the complexity of water flood, which tool can effectively guide asset teams towards daily decision-making to improve the reservoir performance. The general workflow is described as below, along with key elements and technologies that comprise it.

\subsection{Step one: Inversion of phase infiltration curve}

The results by Zhang et al. (2013) show that compared with the common water-drive curve, the timing of appearance of curve and line segment of eurytopic water-drive is earlier, the prediction accuracy of which is higher at the same stage of water cut and the water-drive rule and the yield prediction adaptability are stronger. After the production well is in the stable water-drive stage, the relationship between the cumulative oil production and the cumulative water production can be given by

$$
N_{p}=N_{R}-a \frac{N_{p}^{2}}{W_{p}^{q}}
$$

The oil phase index $n_{o}$ and water phase index $n_{w}$ can be solved by $q$

$$
\begin{aligned}
& n_{o}=1+\frac{1}{q} \\
& n_{w}=\frac{2}{q}-1
\end{aligned}
$$

The oil-phase relative permeability and water-phase relative permeability (Zhang et al., 2018) can be calculated by

$$
\begin{gathered}
K_{r w}\left(S_{w}\right)=K_{r w}\left(S_{o r}\right) S_{w d}{ }^{n_{w}} \\
K_{r o}\left(S_{w}\right)=K_{r o}\left(S_{w i}\right)\left(1-S_{w d}\right)^{n_{o}} \\
S_{w d}=\frac{S_{w}-S_{w i}}{1-S_{w i}-S_{o r}}
\end{gathered}
$$

where $N_{p}$ is the cumulative oil production, $10^{4} \mathrm{~m}^{3} ; N_{R}$ is the petroleum geological reserves, $10^{4} \mathrm{~m}^{3} ; W_{p}$ is the cumulative water production, $10^{4} \mathrm{~m}^{3} ; a, q$ is the undetermined coefficients, which can be solved by production dynamic data inversion, respectively; $n_{o}$ is the oil phase index, dimensionless; $n_{w}$ is the water phase index, dimensionless; $K_{r w}\left(S_{w}\right)$ is the water-phase relative permeability, $\mathrm{mD} ; K_{r w}\left(S_{o r}\right)$ water-phase relative permeability under residual oil saturation, $\mathrm{mD} ; S_{w d}$ is the normalized water saturation, dimensionless; $K_{r o}\left(S_{w}\right)$ is the oil-phase relative permeability, $\mathrm{mD} ; K_{r o}\left(S_{w i}\right)$ is the oil-phase relative permeability under the irreducible water saturation, $\mathrm{mD} ; S_{w}$ is the water saturation, dimensionless; $S_{w i}$ is the initial water saturation, dimensionless; $S_{o r}$ is the residual oil saturation, dimensionless.

Reservoir property is reflected by morphological character of relative permeability curve. So, the heterogeneity of the reservoir in this area can be plotted by inversion of relative permeability curve for all production wells in the development area. 


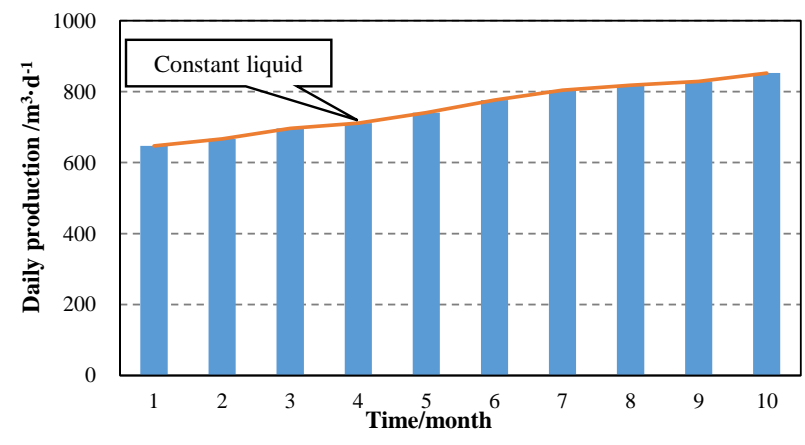

Fig. 1. Change law of daily fluid production in single well.

\subsection{Step two: Production well production forecast}

The prediction of single well production depends mainly on the initial value and the oil production decline rate, while the decline rate is the key and the details are as follows:

\section{(1) Determination of decline rate}

In the development process of general production wells, the daily liquid production and water cut increases, while the daily oil production gradually decreases. But if the whole development process is differentiated into time, it is assumed that the daily oil production is unchanged for each time period, that is, the production conditions of the fixed liquid amount are satisfied, such as Fig. 1.

The production at the next time is calculated by using the formula of decline rate under the condition of fixed liquid production (Liu, 2016):

$$
D_{t}=\frac{Q_{l}}{N_{R}} f_{w}^{\prime}
$$

where $D_{t}$ is the annual decline rate, dimensionless; $Q_{l}$ is the annual production of liquid, $10^{4} \mathrm{~m}^{3} ; f_{w}^{\prime}$ is the water cut derivative, dimensionless.

\section{(2) Theoretical production forecast}

A new method for calculating the theoretical production of a single production well is as follows:

(a) According to step one, the relative permeability curve of single well (Zhang et al., 2018) is obtained to calculate index of dimensionless liquid production $J_{D l}$ and index of dimensionless oil production $J_{D o}$ expressed as, respectively

$$
\begin{gathered}
J_{D l}=\frac{K_{r o}}{K_{r o}\left(S_{w i}\right)}+\frac{K_{r w} B_{o} \mu_{o}}{K_{r o}\left(S_{w i}\right) B_{w} \mu_{w}} \\
J_{D o}=J_{D l}\left(1-f_{w}\right)
\end{gathered}
$$

where $\mu_{o}$ is the viscosity of oil phase, $\mathrm{mPa} \cdot \mathrm{s} ; B_{o}$ is the oil volume factor, $\mathrm{m}^{3} / \mathrm{m}^{3} ; \mu_{w}$ is the viscosity of water phase, $\mathrm{mPa} \cdot \mathrm{s} ; B_{w}$ is the water volume factor, $\mathrm{m}^{3} / \mathrm{m}^{3} ; f_{w}$ is the water cut, dimensionless.

(b) Gotten daily oil production $Q_{o, t}$, daily liquid production $Q_{l, t}$ and production pressure difference $\Delta P_{t}$ of the production well at the time $t$.

(c) Calculate the water cut $f_{w t}$, the water cut derivative $f_{w}^{\prime}$, the decline rate $D_{t, t}$, the index of dimensionless liquid production $J_{D l, t}$ and the index of dimensionless oil production $J_{D o, t}$ at the time $t$.

(d) Calculate daily oil production $Q_{o, t+1}$ at the time $t+1$ :

$$
Q_{o, t+1}=Q_{o, t}\left(1-D_{t, t}\right)
$$

(e) In a short period of time, it can be approximately considered that the production well meets the production conditions of fixed liquid volume. Then the water cut $f_{w, t+1}$, the water cut derivative $f_{w+1}^{\prime}$, the decline rate $D_{t, t+1}$, the index of dimensionless liquid production $J_{D l, t+1}$ and the index of dimensionless oil production $J_{D o, t+1}$ can be obtained at the time $t+1$.

(f) Assuming that the production pressure difference at time $t+1$ is $\Delta P_{t+1}$, then the liquid volume change $\varphi$ at time $t+1$ is:

$$
\varphi=\frac{J_{D l, t+1} \Delta P_{t+1}}{J_{D l, t} \Delta P_{t}}
$$

(g) Assuming that the water cut remains the same, the daily liquid production and oil production at the time $t+1$ are given by, respectively

$$
\begin{gathered}
Q_{l, t+1}=\varphi Q_{l, t} \\
Q_{o, t+1}=\varphi Q_{o, t+1}
\end{gathered}
$$

(h) The well per-production is calculated according to step (b) to $(\mathrm{g})$ to the specified last time. The specific process is shown in Fig. 2.

\subsection{Step three: Determination of the injection rate of the injection well}

In order to strike the balance of injection and production and improve the development of water flooding, the injection volume of the injection well should be adjusted with the adjustment of the production volume in beneficiary wells. The injection volume of the injection well depends on the reasonable injection-production ratio and the well allocation factors (WAFS) between the beneficial production wells. It is necessary to consider the effective recovery and maintenance of formation pressure for determining the reasonable injectionproduction ratio while the over-rapid growth of the corresponding oil production well water cut is not caused by the material balance method and reservoir numerical simulation.

Dividing coefficient indicates the correlation coefficient between the allocation of water injection wells and the liquid production of the surrounding beneficiary wells. The results show that the WAFS obtained by streamline numerical simulation method (Thiele et al., 1996; Bostan et al., 2013; Tailai et al., 2014; Sajjadi et al., 2017) in Fig. 3 is more accurate, which can be expressed as

$$
W A F_{i l}=100 \sum_{j=1}^{n_{p}} \sum_{k=1}^{n_{s l}} \frac{q_{j i l}^{k}}{q_{i}^{w}}
$$




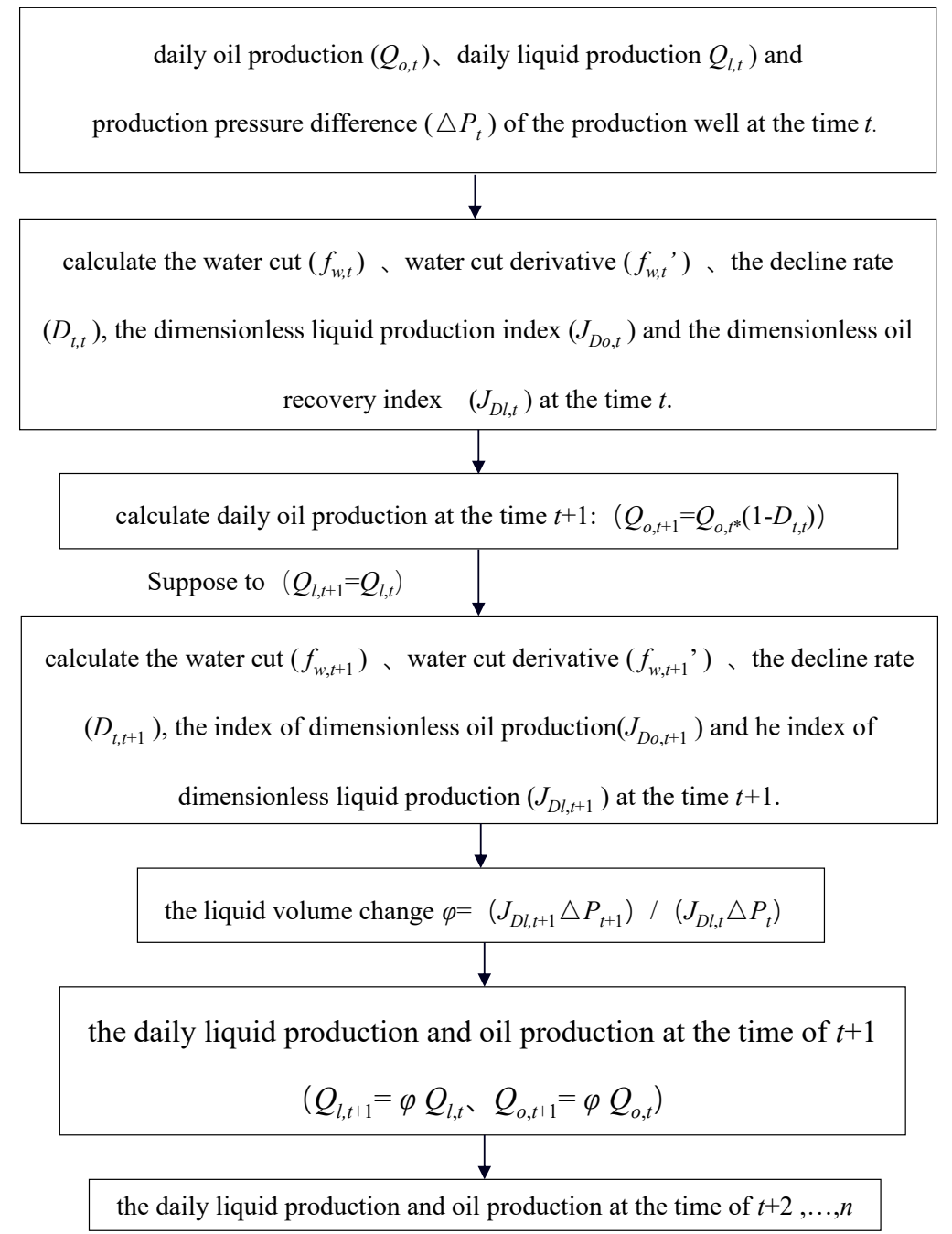

Fig. 2. Flow chart of single well production prediction.
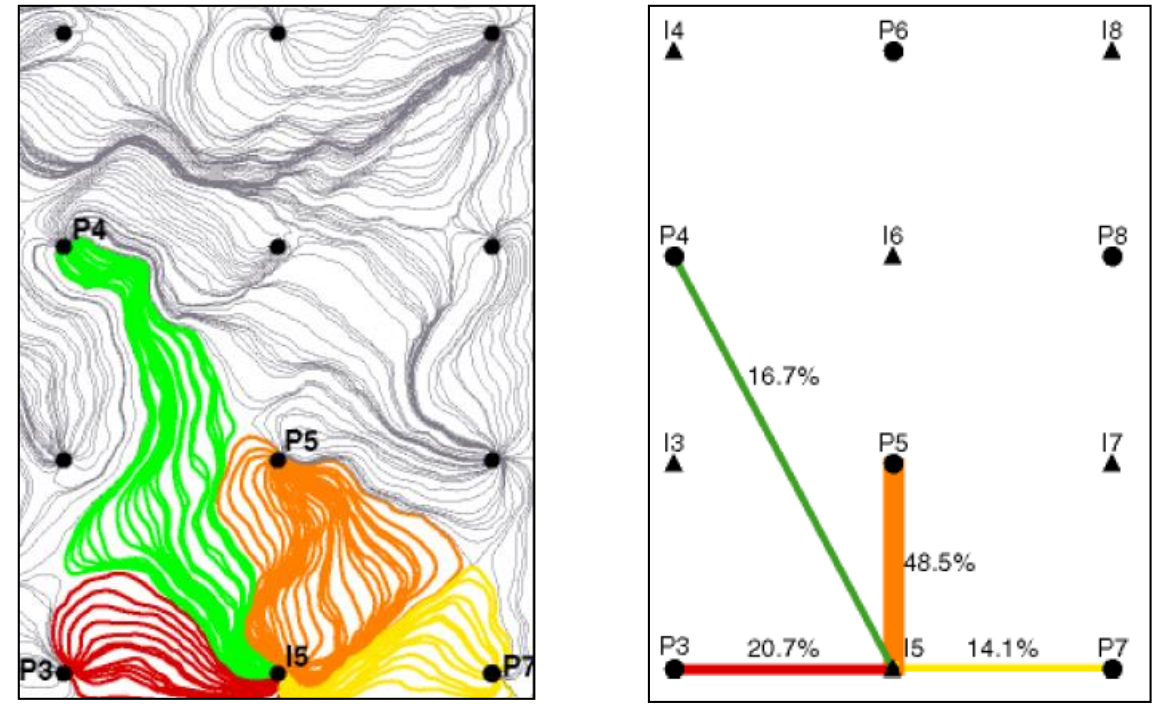

Fig. 3. Sketch of determination of the well allocation factors. 


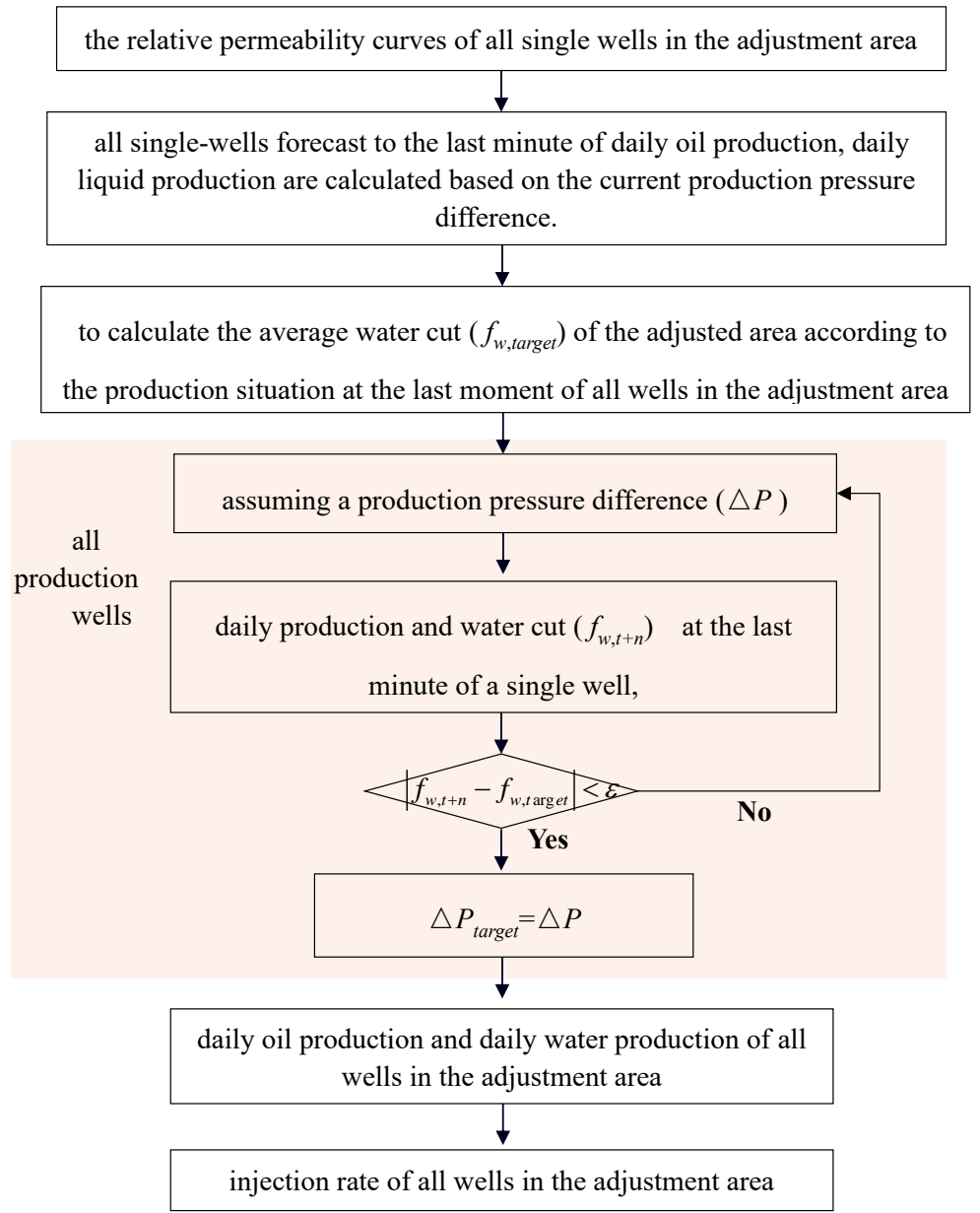

Fig. 4. Flow chart of single well production pressure difference calculation.

where $W A F_{i l}$ is a well allocation factor at the injection well $i$ due to support from the production well $l, n_{p}$ is the number of fluid phase, $n_{s l}$ is the number of streamlines between two wells, $q_{i}^{w}$ is the total flow rate of the injection well $i, \mathrm{~m}^{3} / \mathrm{d}$, $q_{j i l}^{k}$ is the phase $j$ flux of streamline $k$ between wells $i$ and $l$ at well $i, \mathrm{~m}^{3} / \mathrm{d}$.

After determining the injection-production ratio and the WAFS of well group, the injection rate can be obtained by

$$
Q_{i}=I P R \sum_{j=1}^{n} W A F_{i j}\left(B_{o} Q_{o, j}+Q_{w, j}\right)
$$

where $W A F_{i j}$ is a well allocation factor at the injection well $i$ due to support from the production well $j, Q_{i}$ is the injection day if the injection well $i, \mathrm{~m}^{3} / \mathrm{d} ; I P R$ is the injection-production ratio, $Q_{o, j}$ is the daily oil production of the production well $j, \mathrm{~m}^{3} / \mathrm{d} ; Q_{w, j}$ is the daily water production of the production well $j, \mathrm{~m}^{3} / \mathrm{d} ; n$ is the number of production wells that benefit the injection well $i$.

\subsection{Step four: Injection and production adjustment in the plane}

Equilibrium displacement refers to the same degree of displacement (residual oil saturation) in all directions of the reservoir. If the displacement degree of each injectionproduction well in the reservoir is equal, the displacement is called partial equilibrium displacement. For reservoirs in high water cut stages, according to the fractional flow equation and Welge equation (Zhang et al., 2018), we can see that the relationship between average water saturation and water cut of production wells is written as

$$
f_{w}=1-\left[\frac{1-S_{o r}-\overline{S_{w}}}{\omega\left(1-S_{o r}-S_{w i}\right)}\right]^{\frac{1}{1-\omega}}
$$

where $\overline{S_{w}}$ is the average water saturation between the injection and production wells, dimensionless; $\omega$ is the Welge equation coefficient, dimensionless.

Therefore, within given regulatory time, remaining oil saturation is identical, which means the same average water saturation between injection and production wells. According to Eq. (16), if each oil well reaches the same water cut, it can conclude that equilibrium displacement is achieved. Then, aiming at achieving the same water cut in all wells, the realtime optimization adjustment of injection and production can be carried out. In this study, C \# language is used to prepare the adjustment process of plane equilibrium displacement injection and mining as shown in the Fig. 4. The specific process is as follows: 


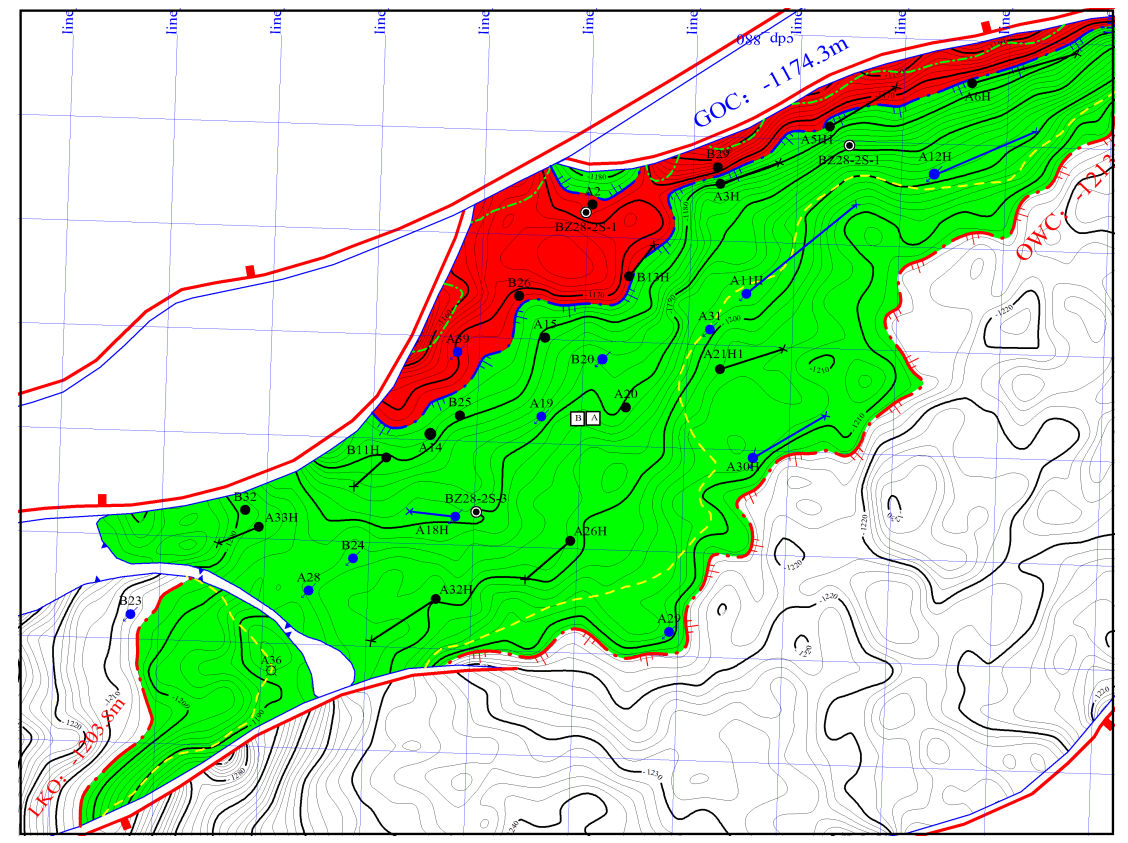

Fig. 5. Well location of 1-1195-1 sand body.

(a) The relative permeability curves of all single wells in the adjustment area are inversed according to the production dynamic data by the presented method shown in step one.

(b) According to the method shown in step two, all singlewells forecast to the last minute of daily oil production, and daily liquid production are calculated based on the current production pressure difference.

(c) To calculate the average water cut of the adjusted area according to the production situation at the last moment of all wells in the adjustment area, which is the target water cut in a given time.

(d) Assuming that the production pressure difference is for every well, according to the method shown in step two, calculate the daily liquid production, the daily oil production and water content are one at the last minute, and judge whether the water content meets the target water content at the last minute. If the water cut is greater than the target water cut, then the production pressure difference is to be reduced. If the water cut is less than the target water cut, the production pressure difference will be enlarged until the requirements are satisfied. By this method, the production pressure difference needed for each well in the adjustment area to reach the target water cut is obtained.

(e) The adjusted daily oil production and daily water production of all wells can be obtained according to the production pressure difference determined by the above production wells.

(f) Injection rate after adjustment can be determined according to the production data of production wells, injectionproduction ratio and the WAFS of well groups.

\section{Case Study}

The petroleum geological reserves of 1-1195-1 sand body
(Fig. 5) in Bohai BZ Oilfield are $773.36 \times 10^{4} \mathrm{~m}^{3}$. The average effective thickness of the reservoir is $6.4 \mathrm{~m}$, the average porosity is $31.0 \%$, and the average permeability is $2381 \mathrm{mD}$. At present, there are 12 production wells and 9 water injection wells based on development of irregular well pattern with single sand body. In December 2017, the daily liquid production of sand bodies was $3306 \mathrm{~m}^{3} / \mathrm{d}$, the daily oil production was $530 \mathrm{~m}^{3} / \mathrm{d}$ and the water cut was $83.9 \%$. The output of the production well in the plane is uneven, with daily liquid production ranging from 104 to $542 \mathrm{~m}^{3} / \mathrm{d}$ and single-well water cut ranging from $57.7 \%$ 90.1\%. In order to improve development effect of dominant channels, the sand body is set up to realize equilibrium displacement based on its production situation while the adjustment of injection-production is to be carried out by four years.

Here, a single well phase permeation inversion shown in Fig. 6 and production prediction shown in Fig. 7 are taken as an example to illustrate the process of achieving balanced displacement, based on which all production well adjustment strategies shown in Table 1 are completed.

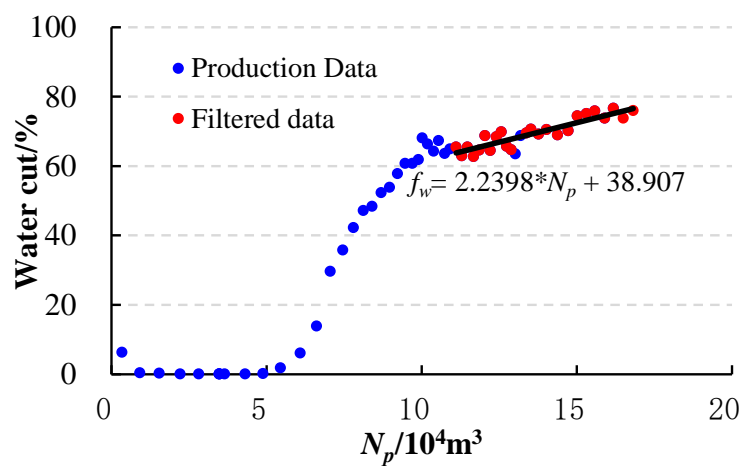

(a) 
Table 1. Adjustment of 1-1195-1 sand body production wells.

\begin{tabular}{|c|c|c|c|c|c|c|c|c|c|}
\hline \multirow[b]{2}{*}{$\begin{array}{l}\text { Production } \\
\text { Well }\end{array}$} & \multicolumn{4}{|c|}{ Current production situation } & \multicolumn{2}{|c|}{ Pre-adjustment } & \multicolumn{2}{|c|}{ After-adjustment } & \multirow[b]{2}{*}{$\begin{array}{l}\text { Adjustment } \\
\text { measures }\end{array}$} \\
\hline & $\begin{array}{l}\text { Liquid } \\
\text { rate/ } \\
\left(\mathrm{m}^{3} \cdot \mathrm{d}^{-1}\right)\end{array}$ & $\begin{array}{l}\text { Oil } \\
\text { rate/ } \\
\left(\mathrm{m}^{3} \cdot \mathrm{d}^{-1}\right)\end{array}$ & $\begin{array}{l}\text { Water } \\
\text { cut/ } \\
\%\end{array}$ & $\begin{array}{l}\text { Production } \\
\text { pressure } \\
\text { difference/ } \mathrm{MPa}\end{array}$ & $\begin{array}{l}\text { Water } \\
\text { cut/ } \\
\%\end{array}$ & $\begin{array}{l}\text { Production } \\
\text { pressure } \\
\text { difference/ } \mathrm{MPa}\end{array}$ & $\begin{array}{l}\text { Water } \\
\text { cut// } \\
\%\end{array}$ & $\begin{array}{l}\text { Production } \\
\text { Production } \\
\text { difference/ } \mathrm{MPa}\end{array}$ & \\
\hline $\mathrm{A} 32 \mathrm{H}$ & 356 & 62 & 82.6 & 0.50 & 86.8 & 0.50 & \multirow{7}{*}{91.1} & 2.08 & increasing \\
\hline $\mathrm{B} 11 \mathrm{H}$ & 221 & 73 & 67.0 & 0.53 & 84.4 & 0.53 & & 0.39 & increasing \\
\hline B13H & 243 & 80 & 67.1 & 0.34 & 89.3 & 0.34 & & 0.54 & increasing \\
\hline $\mathrm{A} 3 \mathrm{H}$ & 442 & 54 & 87.8 & 0.59 & 92.1 & 0.59 & & 0.50 & decreasing \\
\hline A5H1 & 535 & 40 & 92.5 & 2.40 & 95.6 & 2.40 & & 1.29 & decreasing \\
\hline $\mathrm{A} 6 \mathrm{H}$ & 302 & 30 & 90.1 & 1.50 & 94.4 & 1.50 & & 0.50 & decreasing \\
\hline A21H1 & 291 & 30 & 89.7 & 2.52 & 94.1 & 2.52 & & 1.00 & decreasing \\
\hline
\end{tabular}

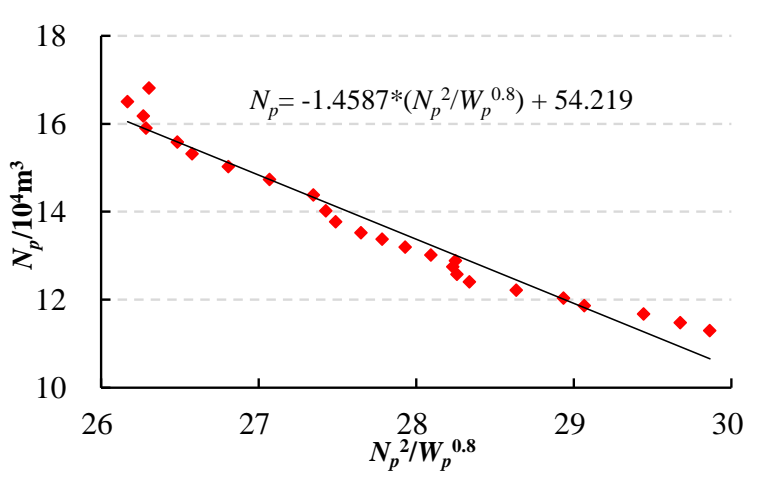

(b)

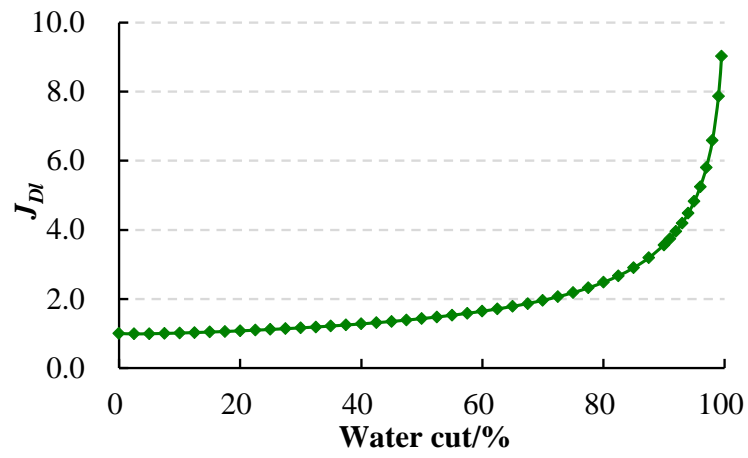

(c)

Fig. 6. Inversion of phase infiltration curve of well A3H. (a) Relationship curve between water cut and cumulative oil production of the well $\mathrm{A} 3 \mathrm{H}(\mathrm{b})$ Common water-drive curve of the well $\mathrm{A} 3 \mathrm{H}$ (c) Relationship curve between dimensionless liquid production index and water cut of the well $\mathrm{A} 3 \mathrm{H}$.

Based on obtaining the relative permeability curve of a single well, it is possible to predict the production of a single well, which is shown in Fig. 7.

According to the adjustment of the production wells and the numerical simulation results of the streamline, the adjust-

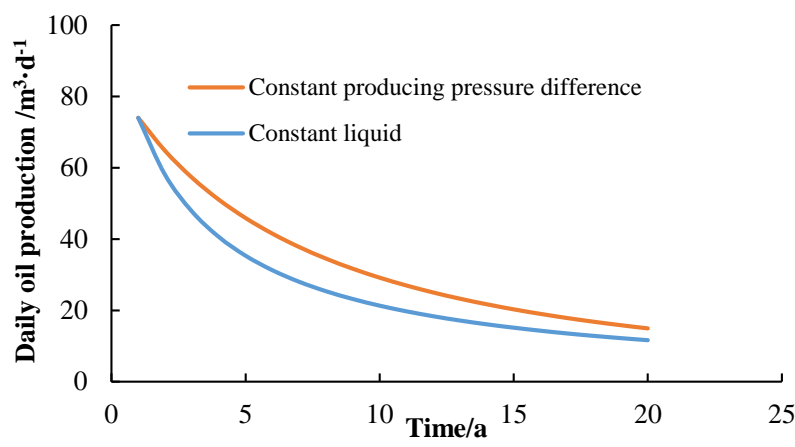

Fig. 7. Production forecast of well A3H.

ment results of injection rate of water injection wells are obtained by means of Eq. (15), with the results being shown in Table 2.

In January 2018, the filed was adjusted by injection and production in the plane based on the above scheme. Seven production wells are increased, while four production wells are decreased, with one well is maintained in the current production state. At the same time, there is increasing the output of five water injection wells, limited injection in three water injection wells while one water injection well maintains the current production state.

In order to better show the optimization of injection and production of sand body, Fig. 8 and Fig. 9 show the curves before and after adjustment of two production wells, with two injection wells shown in Fig. 10 and Fig. 11, all of which are taken as illustrations for explanation.

After the implementation on January 1, 2018, the development effect of sand body gradually improved. The increasing daily oil of sand body is $80 \mathrm{~m}^{3} / \mathrm{d}$, and by the end of 2019 , the increasing cumulative oil has been $2.6 \times 10^{4} \mathrm{~m}^{3}$, realizing the negative reduction of sand body (Fig. 12). Based on the good results of the above applications, real-time injection and 
Table 2. Adjustment of 1-1195-1 sand body injection wells.

\begin{tabular}{llll}
\hline \multirow{2}{*}{ Injection well } & Pre-adjustment & After-adjustment & \multirow{2}{*}{ Adjustment measures } \\
\cline { 2 - 4 } & Injection rate/ $\left(\mathrm{m}^{3} \cdot \mathrm{d}^{-1}\right)$ & Injection rate/ $\left(\mathrm{m}^{3} \cdot \mathrm{d}^{-1}\right)$ & \\
\hline A11H & 800 & 920 & increasing \\
A12H & 693 & 750 & increasing \\
A18H & 609 & 510 & decreasing \\
A19 & 147 & 102 & decreasing \\
A28 & 243 & 181 & decreasing \\
A29 & 246 & 430 & increasing \\
A30H & 155 & 309 & increasing \\
A31 & 185 & 224 & increasing \\
A39 & 156 & 156 & stability \\
\hline
\end{tabular}
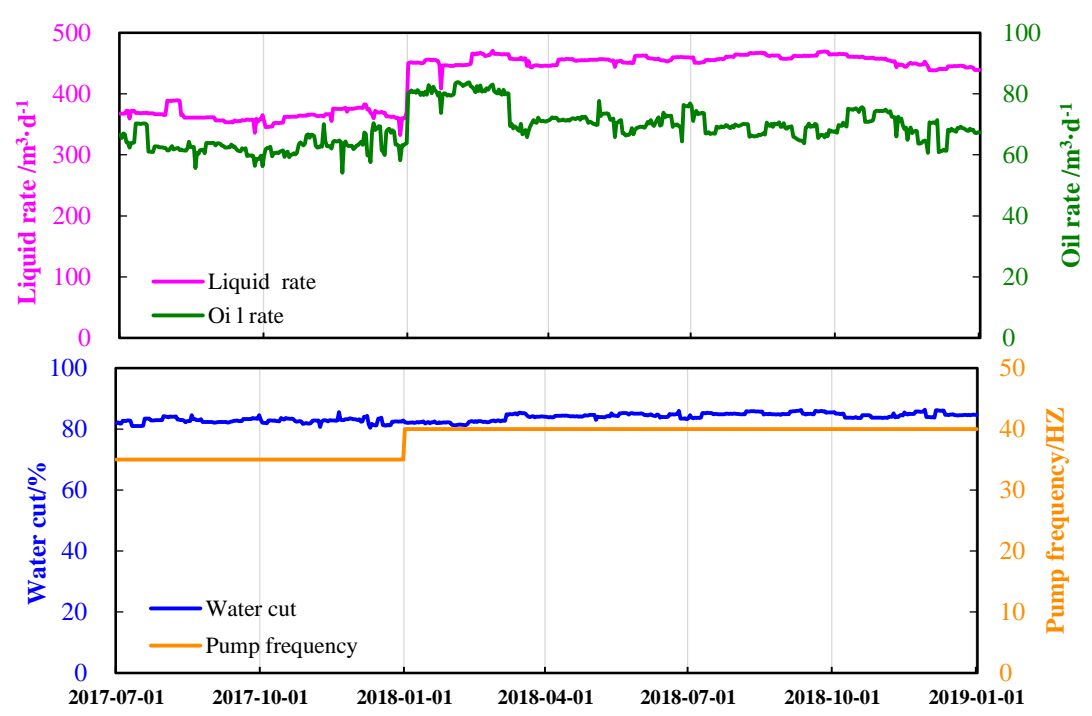

Fig. 8. Production curve before and after the adjustment of well A32H.
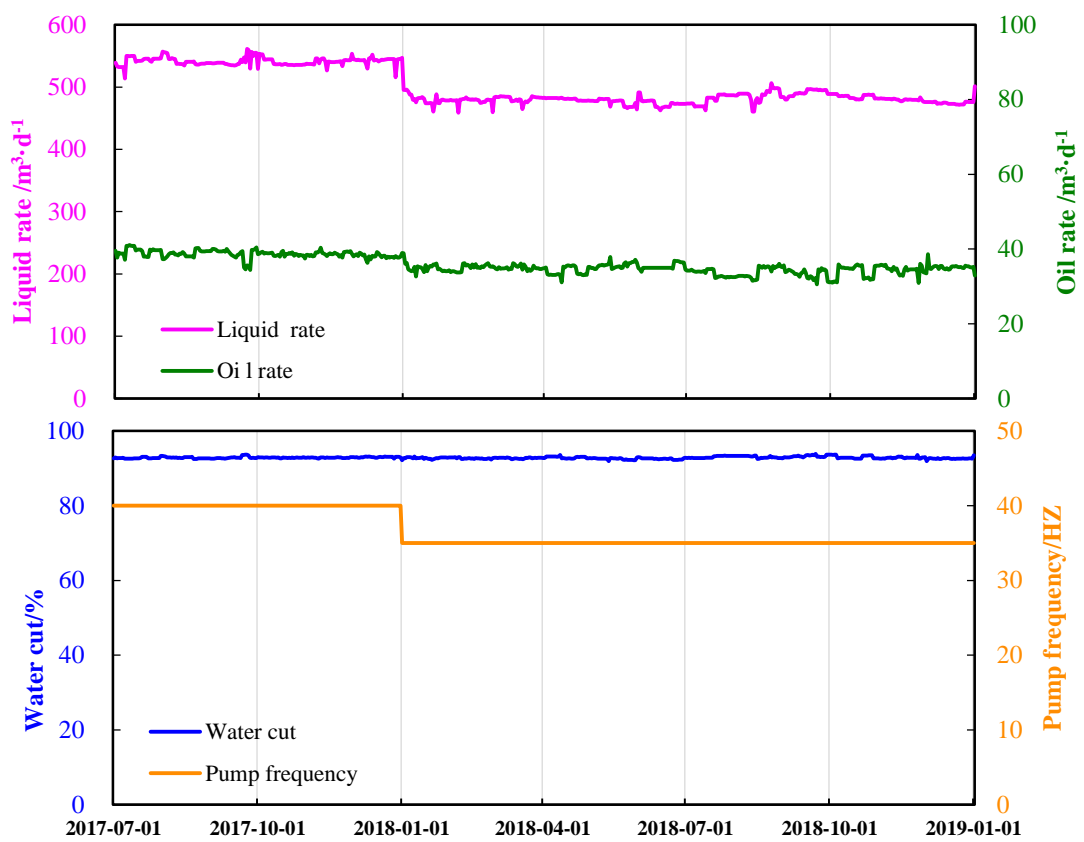

Fig. 9. Production curve before and after the adjustment of well $\mathrm{A} 3 \mathrm{H}$. 


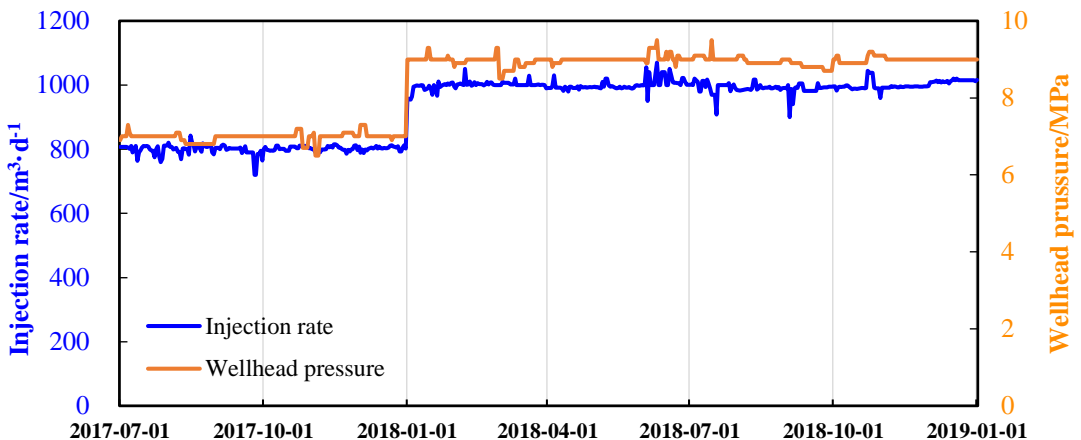

Fig. 10. Injection curve before and after the adjustment of well $\mathrm{A} 11 \mathrm{H}$.

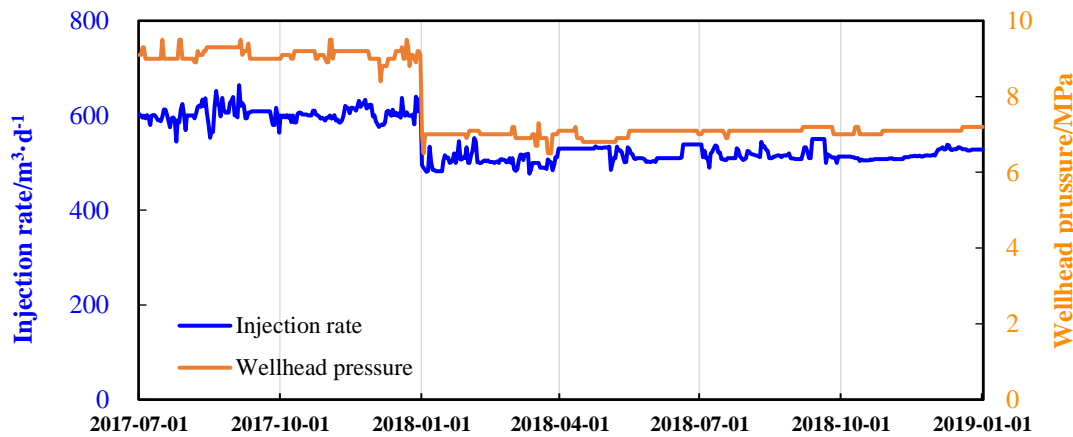

Fig. 11. Injection curve before and after the adjustment of well $\mathrm{A} 18 \mathrm{H}$.

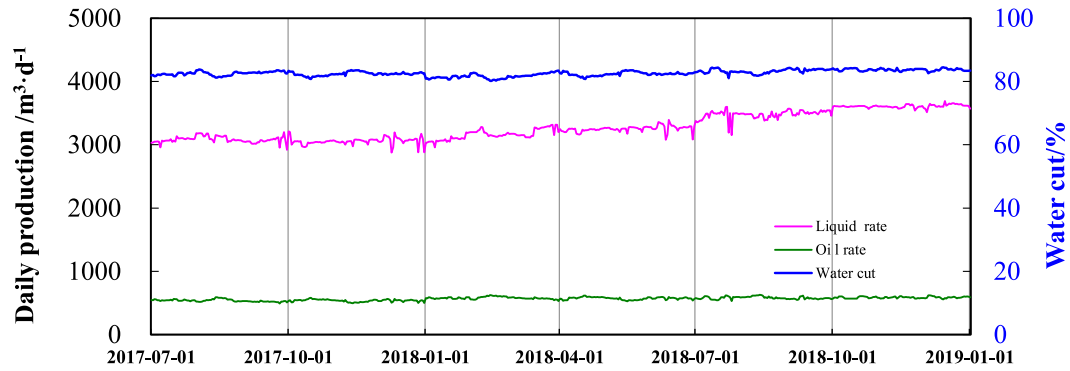

Fig. 12. Production status of 1-1195-1 sand body.

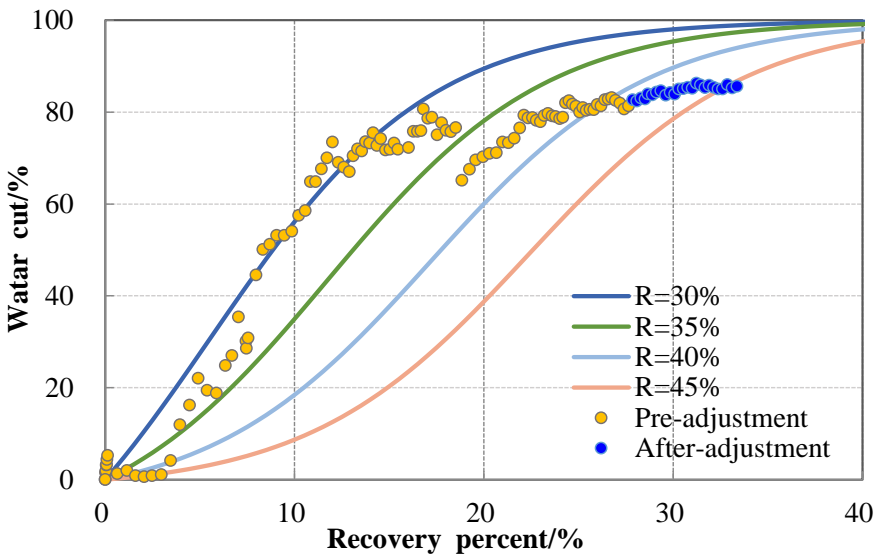

Fig. 13. Tong's curve of 1-1195-1 sand body. 
production optimization is further carried out. As can be seen from the Tong's curve, the development effect continues to improve after adjustment, with the recovery factor increasing from $42 \%$ to $45 \%$ (Fig. 13).

\section{Conclusions}

1) Based on the equation of Buckley-Leverett, combined with the theory of a eurytopic water-drive, a new formula for calculating the production of a single-well is derived. Furthermore, the quantitative characterization relationship of water cut, liquid production and water injection are obtained, with the concept of characterization of reservoir heterogeneity being put forward according to single well phase permeability curve.

2) In view of the same water cut, a new method of plane injection and production adjustment through liquid regulation and injection regulation is presented by adjusting liquid production and water injection, realizing the transformation from single liquid production structure adjustment to equilibrium displacement adjustment.

3) Through the programmed process processing, the application efficiency is improved with formation of equilibrium displacement injection-production adjusting and optimizing software, realizing the real-time optimization and adjustment of injection-production structure.

4) By applying this method to the field test of BZ oilfield in Bohai Sea, the daily oil production of sand body increases by $80 \mathrm{~m}^{3} / \mathrm{d}$ and the cumulative annual oil production increases by $2.6 \times 10^{4} \mathrm{~m}^{3}$, which is of great guiding significance for the adjustment of injection-production structure of Bohai Oilfield.

\section{Acknowledgement}

This work was supported by the Major Projects of CNOOC Ltd in China (YXKY-2018-TJ-04).

\section{Conflict of interest}

The authors declare no competing interest.

Open Access This article, published at Yandy Scientific Press on behalf of the Division of Porous Flow, Hubei Province Society of Rock Mechanics and Engineering, is distributed under the terms and conditions of the Creative Commons Attribution (CC BY-NC-ND) license, which permits unrestricted use, distribution, and reproduction in any medium, provided the original work is properly cited.

\section{References}

Alhuthali, A., Oyerinde, D., Datta-Gupta, A. Optimal waterflood management using rate control. SPE Reserv. Eval. Eng. 2007, 10(5): 539-551.

Artun, E. Characterizing interwell connectivity in waterflooded reservoirs using data-driven and reduced-physics models: A comparative study. Neural Comput. Appl. 2017, 28(7): 1729-1743.

Baker, R.O., Kuppe, F., Chugh, S., et al. Full-field modeling using streamline-based simulation: Four case studies. SPE Reserv. Eval. Eng. 2002, 5(2): 126-134.
Batycky, R.P., Blunt, M.J., Thiele, M.R. A 3D field-scale streamline-based reservoir simulator. SPE Reserv. Eng. 1997, 12(4): 246-254.

Bostan, M., Kharrat, R., Barjas, A. Injection efficiency and water loss optimization using streamline simulation in water flooding process. Pet. Sci. Technol. 2013, 31(14): 1477-1487.

Brouwer, D.R., Jansen, J.D. Dynamic optimization of waterflooding with smart wells using optimal control theory. SPE J. 2004, 9(4): 391-402.

Cao, F., Luo, H., Lake, L.W. Oil-rate forecast by inferring fractional-models from field data with koval method combined with the capacitance/resistance model. SPE Reserv. Eval. Eng. 2015, 18(4): 534-553.

Cardoso, M.A., Durlofsky, L.J. Use of reduced-order modeling procedures for production optimization. SPE J. 2010, 15(2): 426-435.

Chen, Y., Oliver, D.S., Zhang, D. Efficient ensemble-based closed-loop production optimization. SPE J. 2009, 14(4): 634-645.

Denney, D. Use of streamline simulation in reservoir management. J. Pet. Technol. 2001, 53(4): 82-83.

Guo, Z., Reynolds, A.C., Zhao, H. A physics-based datadriven model for history matching, prediction, and characterization of waterflooding performance. SPE J. 2018a, 23(2): 367-395.

Guo, Z., Reynolds, A.C., Zhao, H. Waterflooding optimization with the INSIM-FT data-driven model. Comput. Geosci. 2018b, 22(3): 745-761.

Guo, Z., Reynolds, A.C. INSIM-FT in three-dimensions with gravity. J. Comput. Phys. 2019, 380: 143-169.

Hong, A., Bratvold, R., Nvdal, G. Robust production optimization with capacitance-resistance model as precursor. Comput. Geosci. 2017, 21(5-6): 1423-1442.

$\mathrm{Hu}, \mathrm{J} ., \mathrm{Li}, \mathrm{H}$. Water flooding flowing area identification for oil reservoirs based on the method of streamline clustering artificial intelligence. Pet. Explor. Dev. 2018, 45(2): 328335.

Hu, G. A new method for calculating volumetric sweep efficiency in a water-flooding oilfield. Pet. Explor. Dev. 2013, 40(1): 111-114.

Jansen, J.-D., Brouwer, D., Naevdal, G., et al. Closed-loop reservoir management. First Break 2005, 23(1): 43-48.

Lerlertpakdee, P., Jafarpour, B., Gildin, E. Efficient production optimization using flow-network models. SPE J. 2014, 19(6): 1083-1095.

Liu, M., Zhang, S., Yan, W., et al. How to make injection more effective and get production more optimum-A good case from China. Paper SPE 170996 Presented at SPE Oilfield Water Management Conference and Exhibition, Kuwait city, Kuwait, 21-22 April, 2014.

Liu, Y. A new calculationg method of theoretical decline law for water flooding standstone reservoir. China Offshore Oil and Gas 2016, 28(3): 97-100. (in Chinese)

Mamghaderi, A., Bastami, A., Pourafshary, P. Optimization of waterflooding performance in a layered reservoir using a combination of capacitance-resistive model and genetic algorithm method. J. Energy Resour. Technol. 2013, 
135(1): 013102.

Nguyen, A.P., Lasdon, L., Lake, L.W., et al. Capacitance resistive model application to optimize waterflood in a west texas field. Paper SPE 146984 Presented at SPE Annual Technical Conference and Exhibition, Denver, USA, 30 October-2 November, 2011.

Omara, E.A., EI hawary, A.F., Nosseir, M., et al. Identifying opportunities in a complex mature oil reservoir; a company. Paper Presented at International Petroleum Technology Conference, Doha, Qatar, 19-22 January, 2014.

Park, H.Y., Datta-Gupta, A. Reservoir management using streamline-based flood efficiency maps and application to rate optimization. J. Pet. Sci. Eng. 2013, 109: 312-326.

Sajjadi, S.A., Nasriani, H.R., Dailami, K., et al. Optimizing volumetric sweep efficiency in water flooding by streamline simulation. Energy Sources Part A-Recovery Util. Environ. Eff. 2017, 39: 1-8.

Sayarpour, M., Zuluaga, E., Kabir, C.S., et al. The use of capacitance-resistance models for rapid estimation of waterflood performance and optimization. J. Pet. Sci. Eng. 2009, 69(3-4): 227-238.

Thiele, M.R., Batycky, R.P., Blunt, M.J., et al. Simulating Flow in Heterogeneous Systems Using Streamtubes and Streamlines. SPE Reserv. Eng. 1996, 11(1): 5-12.

Van Essen, G., Zandvliet, M., Van den Hof, P., et al. Robust waterflooding optimization of multiple geological scenarios. SPE J. 2009, 14(1): 202-210.
Wen, T., Thiele, M.R., Ciaurri, D.E., et al. Waterflood management using two-stage optimization with streamline simulation. Comput. Geosci. 2014, 18: 483-504.

Yousef, A.A., Gentil, P.H., Jensen, J.L., et al. A capacitance model to infer interwell connectivity from production and injection rate fluctuations. SPE Reserv. Eval. Eng. 2006, 9(6): 630-646.

Zhang, J., An, R., Xu, J., et al. Analyzing the applicability of an eurytopic water-drive curve and its extensible applications. China Offshore Oil and Gas 2013, 25(6): 55-60. (in Chinese)

Zhang, J., Yang, R. A further study on Welge equation. Energy Explor. Exploit. 2018, 36(5): 1103-1113.

Zhao, H., Kang, Z., Zhang, X., et al. A physics-based datadriven numerical model for reservoir history matching and prediction with a field application. SPE J. 2016, 21(6): 2175-2194.

Zhao, H., Xu, L., Guo, Z., et al. A new and fast waterflooding optimization workflow based on INSIM-derived injection efficiency with a field application. J. Pet. Sci. Eng. 2019, 179: 1186-1200.

Zhao, H., Xu, L., Zhang, Q., et al. Flow path tracking strategy in a data-driven interwell numerical simulation model for waterflooding history matching and performance prediction with infill wells. SPE J. 2020, 25(2): 10071025. 